\title{
Mathematical Modeling of Diaphragm Pneumatic Motors
}

\author{
Kamil Fojtášek ${ }^{1, a}$, Lukáš Dvořák ${ }^{1}$ \\ ${ }^{1}$ VŠB-Technical University of Ostrava, Faculty of Mechanical Engineering, Department of Hydrodynamics and Hydraulic \\ Equipment, 17. listopadu 15/2172, Ostrava 70833, Czech Republic
}

\begin{abstract}
Pneumatic diaphragm motors belong to the group of motors with elastic working parts. This part is usually made of rubber with a textile insert and it is deformed under the pressure of a compressed air or from the external mass load. This is resulting in a final working effect. In this type of motors are in contact two different elastic environments - the compressed air and the esaltic part. These motors are mainly the low-stroke and working with relatively large forces. This paper presents mathematical modeling static properties of diaphragm motors.
\end{abstract}

\section{Introduction}

The diaphragm motors Figure 1 are linear actuators, produced in single and double acting versions. Single action motor has built-in a strong spring that ensures backward movement of motor. For applications requiring force effect in both directions, there are used double acting type. Elastic part - the membrane is usually made of rubber, which is reinforced with textile inserts. These motors are used for the realization of small rectilinear movements at relatively high transmitted force, with low friction and perfect tightness. More about the properties and structure of diaphragm pneumatic motor is shown in [1]. Various types of the membranes are usually used in the regulatory elements and systems. However in this paper we will discuss diaphragm motor as a actuator power unit. For a description of the behavior and subsequent mathematical modeling of this motor, at first it is necessary to determine the static properties.

\section{Basic equations}

Diaphragm motors belong to the group of elements with elastic working member. Properties of each elastic element (springs, etc.) are described in the deformation, namely dependence of load on deformation. In the case of an elastic membrane, there is effective (actual) area a basic characteristic is. Effective membrane area under the action of a pressure difference (pressure drop) of fluid creating the real force in axial direction on membrane solid central plate. Comparison of effective membrane area with an equivalent area of the linear piston motors are not quite accurate. The effective membrane area can take the deformation values positive, zero or negative, which contradicts the concept of the piston area. Identification and derivation of effective membrane area was described detailed in [2]. The paper presents only the resulting equations, which are a base of a mathematical model.
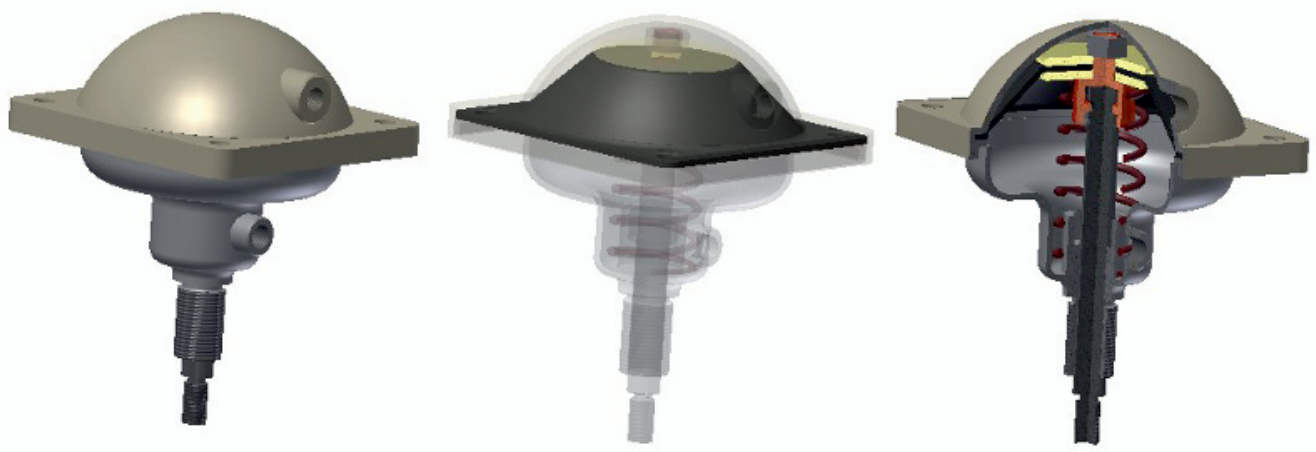

Figure 1. Diaphragm motor

\footnotetext{
${ }^{\mathrm{a}}$ Corresponding author: kamil.fojtasek@seznam.cz
} 
Generally in the literature such as [3] gives a formula for calculating the effective membrane area of the form:

$$
S_{e f 1}=\frac{\pi}{12}\left(D^{2}+D \cdot d+d^{2}\right)
$$

where: $D$ the diameter of fixed end membrane into the housing,

$d$ the diameter of the solid center.

This calculation is obtained by assuming that the diaphragm is in the middle position (contains negligibly small deflection). One of the basic problems of elastic membranes as a working elements is the stability of their effective area. Frequently experiments show that the change in the effective area of the membrane depends on two main causes: from moving a solid center and from the pressure change.

To determine the general rules describing the changes effective area of elastic membrane is based on the assumption: that the force of air pressure divided between the fixed end and solid center. Elastic membrane surface transmits on a solid center in the axial direction the force $G$ which is evenly divided by diameter solid central plate. We assume that the membrane has no bending stiffness. Then the membrane can't produce other force in addition to the tensile force $T$ in meridian direction. On the solid central plate transmits only this force and force $G$ is the vertical component Figure 2.

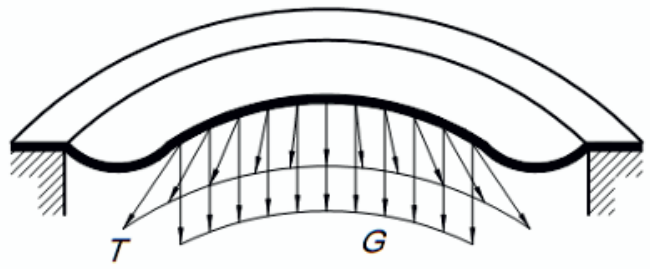

Figure 2. The part of the elastic membrane area

Expression of the force effect and the subsequent adjustment of the equation (1) into a form that respects the repositioning of solid center:

$$
S_{e f}=\frac{\pi}{12} \cdot\left(D^{2}+D \cdot d+d^{2}\right)+\frac{\pi \cdot(D+2 d)}{6} \cdot \frac{x}{\tan \varphi}
$$

where: $x$ is stroke (change of position solid center), $\varphi$ is membrane deflection angle.

The first member of equation (2) represents the formula of the effective membrane area at neutral position of solid center, therefore without pressure. The second term of the equation represents the change in the effective area by deflection $\mathrm{x}$ from the neutral position.

In this equation are two unknowns, stroke $x$ and the membrane deflection angle $\varphi$, which are indicated in the diagram Figure 3 for the determine the effect force acting on the membrane.

The angle $\varphi$ can be derived using geometric modifications as the angle of the circular arc in the form:

$$
\varphi=\frac{l \cdot \sin \varphi}{\sqrt{\left(\frac{D-d}{2}\right)^{2}+x^{2}}}
$$

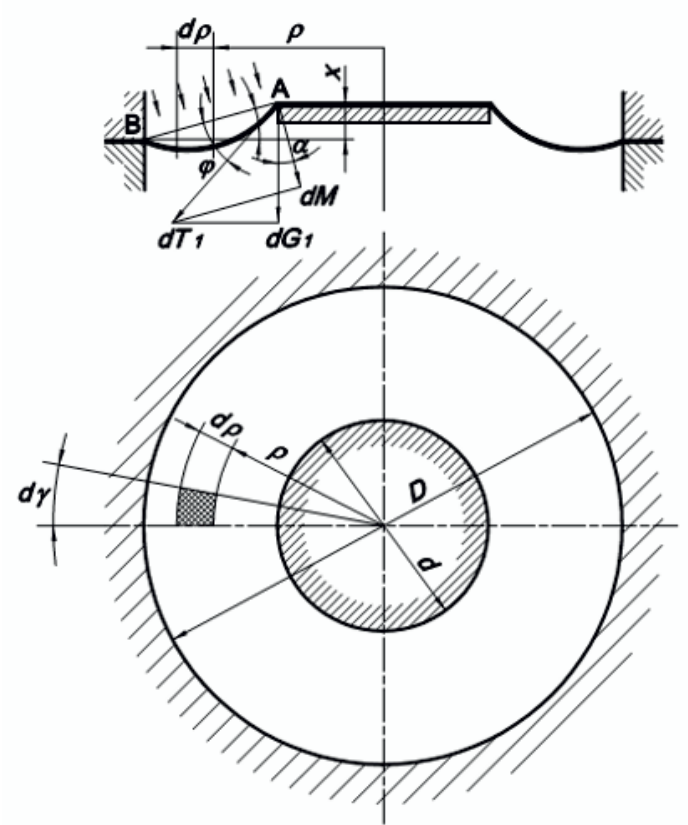

Figure 3. Scheme for the calculation of forces in membrane from the influence of the displacement of solid center

In equation (3) also contained the sine of the angle, usually indicates a modified conversion formula for $0 \leq \varphi \leq \frac{\pi}{2}$ in the form [4]:

$$
\frac{\sin \varphi}{\varphi}=\frac{\sqrt{\left(\frac{D-d}{2}\right)^{2}+x^{2}}}{l}
$$

If we consider even influence the pressure $p$ on the membrane, it enters equation (3) in the form:

$$
\varphi_{1}=\frac{l \cdot \sin \varphi}{\sqrt{\left(\frac{D-d}{2}\right)^{2}+x^{2}}}+\frac{p \cdot l}{2 \cdot E \cdot \delta}
$$

where: $E$ module of elasticity (membrane),

$\delta$ membrane thickness,

$l$ length deflection of the membrane.

Together with the determination of the effective area is one of the basic specific features stiffness and the related sensitivity of elastic membranes. It is a advantageous to define these values especially when the membrane does not operate in full stroke. This is essentially a membrane, working under force compensation. The stiffness of the membrane can be expressed after modifications in the form:

$C=\frac{\pi \cdot p \cdot(D+2 d)}{6} \cdot\left[\cot \varphi+\frac{x^{2} \cdot \varphi^{3}}{l^{2} \cdot(\sin \varphi-\varphi \cdot \cos \varphi) \cdot \sin ^{3} \varphi}\right]$

Sensitivity membrane is inverse value of stiffness and can be expressed by equation (6):

$$
\lambda=\frac{1}{C}
$$


Detailed description of the behavior of diaphragm motors, including the derivation of the equation is given in [5].

\section{Mathematical modeling of membrane motors}

In the literature, such as [6] is shown the general problem of mathematical modeling of fluid systems which are described by thermodynamic and kinetic equations. On the base of those equations we can describe the static and dynamic behavior of the element or system. However, specific design and function of pneumatic motors with elastic working parts does not allow modelling based on generally accepted practices and for each type of motor is to be treated individually.

For the mathematical modeling of static diaphragm motors properties were selected software MatlabSimulink. Using of theoretical equations this program allows quite accurately describe the behavior of these motors. From the perspective of the design and function of diaphragm motor, the most similar is single acting pneumatic motor with a return spring. It is assumed that area on the spring side is connected to the atmosphere and reverse motion is caused only by spring action. However, in diaphragm motor is reverse motion also influenced by elastic part the membrane. We can infer from the classical equations of motion of single acting motor, but with the need to modify this equation. In this work we discussed the creation of static characteristics. The most important characteristic is the force $F$ dependence on stroke $x$. It is appropriate to modify the equation of motion for the force equation, with an expression of static force $F_{S}$.

According to Figure 4, you can write that:

$$
F_{s}=F_{1}-F_{2}-F_{3}-F_{4}
$$

Force $F_{1}$ is exerted in meeting workspace motor, by a pressure of compressed air to the effective area:

$$
F_{1}=p_{1} \cdot S_{e f}
$$

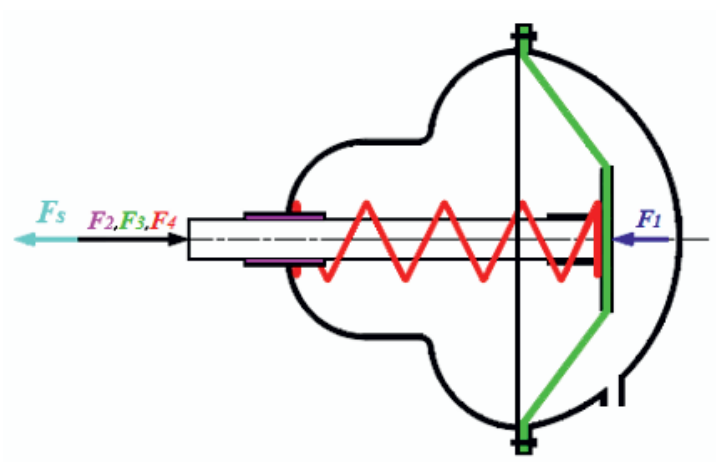

Figure 4. Scheme to express force effects of membrane motor

In the creation static characteristics is obviously a constant working pressure $p_{1}$, and $S_{e f}$ is effective membrane area, which was described by the equation (2). In this equation enters as a variable stroke $x$ and it depends angle $\varphi$, defined by equations (3-5).

Against the motion of piston (diaphragm) there are three force effects. Friction force $F_{2}$ on the piston rod which we can replace by a passive resistance $R_{0}$ as a part of loading force $F_{z}$.

$$
F_{2}=R_{0}=a \cdot F_{z}
$$

where the force $F_{Z}$ is:

$$
F_{z}=\frac{p_{1} \cdot \frac{\pi \cdot D^{2}}{4}}{1+a}
$$

The coefficient $\alpha$ takes into account the effect of friction. For common pneumatic motors it's value is in the range $a=0.1 \div 0.3$.
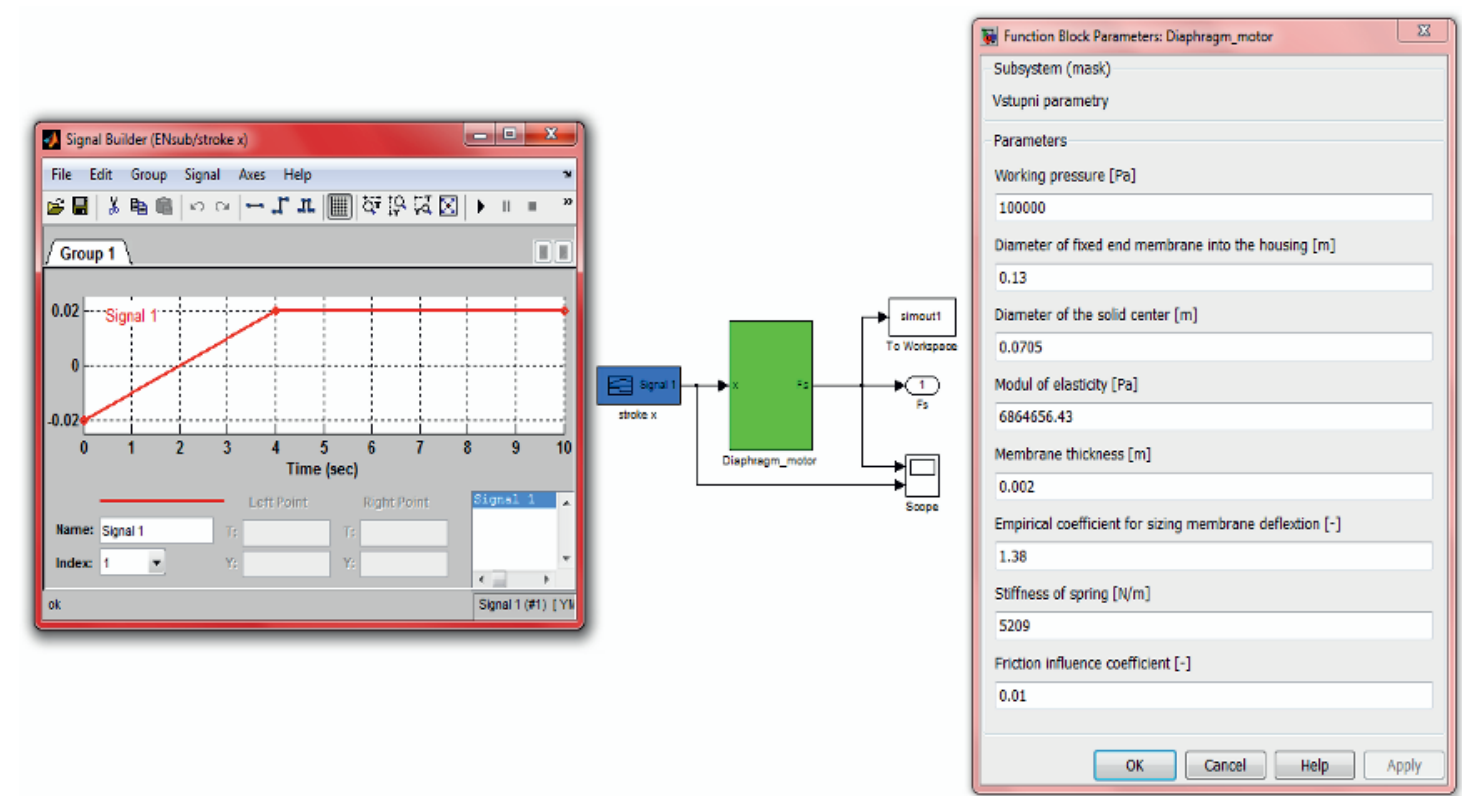

Figure 5. The main subsystem of diaphragm motor 


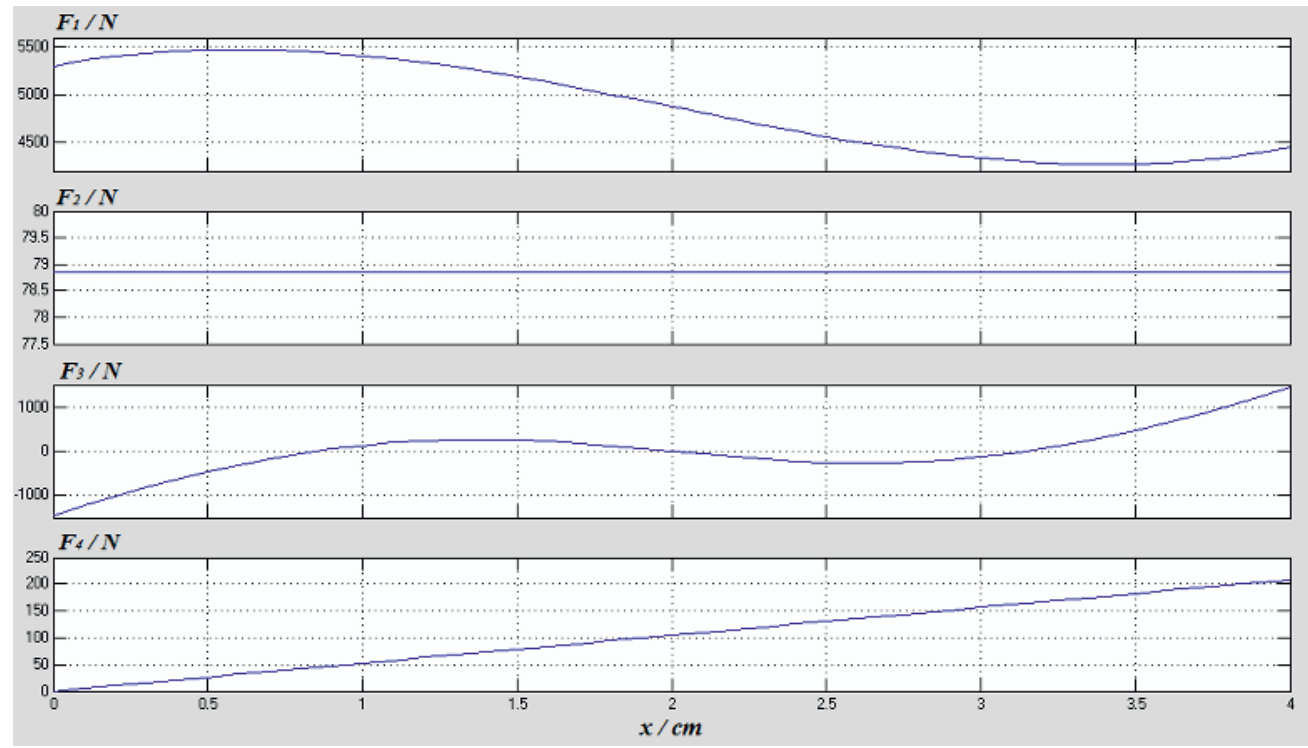

Figure 6. Graphical representation of the diaphragm motor force effects

Diaphragm motors are characterized by low values of friction losses. Unlike classical pneumatic motor there is only piston rod in contact with the cylinder body and only on a very small surface. For this reason the coefficient $a$ was set on value 0.01 in the models.

Force $F_{3}$ includes stiffness of the membrane:

$$
F_{3}=C \cdot x
$$

The calculation of stiffness membrane $C$ is shown in equation (6), the following equation is evident strong dependence on the angle $\varphi$.

Last force $F_{4}$ arises from the stiffness of the spring $k$, and this value is to be determined experimentally:

$$
F_{4}=k \cdot x
$$

In Figure 5 is shown the main subsystem in MatlabSimulink, on the right side are defined all input parameters of diaphragm motor through which resultant force is calculated.

In the left part of the model is specified stroke $x$ by the signal builder block. It is a linear dependence. The value of time step does not have any meaning for static problems and was chosen with regard to stroke and subsequent graphical representation in the model. For diaphragm motor with stroke $x=0 \div 0.04 \mathrm{~m}$ the simulation time was 4 seconds.

In Matlab-Simulink can be also graphically illustrate the individual effects of the total static force $F_{s}$, depending on the stroke $x$, Figure 6. It is a diaphragm motor Rexroth 1020100000, at constant pressure $p_{1}=6 \mathrm{bar}$. Influence of friction the force $F_{2}$, is characterized by a constant and relatively minor size. Interesting is a comparison of forces $F_{3}$ and $F_{4}$ ie spring force and membrane stiffness. While the stiffness of the spring is a traditional linear, stiffness of membrane is partially linear features only near "zero" stroke, so when overshoot membranes within the cylinder.
Figure 7 shows the static force $F_{s}=f(x)$ in the whole range of constant input pressure $p_{1}$.

To verify the results of mathematical models it was necessary to establish an experimental device for measuring the static characteristics of the diaphragm motors. The proposed device has been previously described in [7]. Figure 8 shows detailed scheme of the measuring device. Behind the source of compressed air are located button $3 / 2$ distributors R1 and R2, which are used to supply compressed air to the measured and burdening motor. In the upper branch is located reducing valve RV which is used to set the load forces on the air bellow motor ZM and before this motor is the sensor of back pressure $p_{2}$.

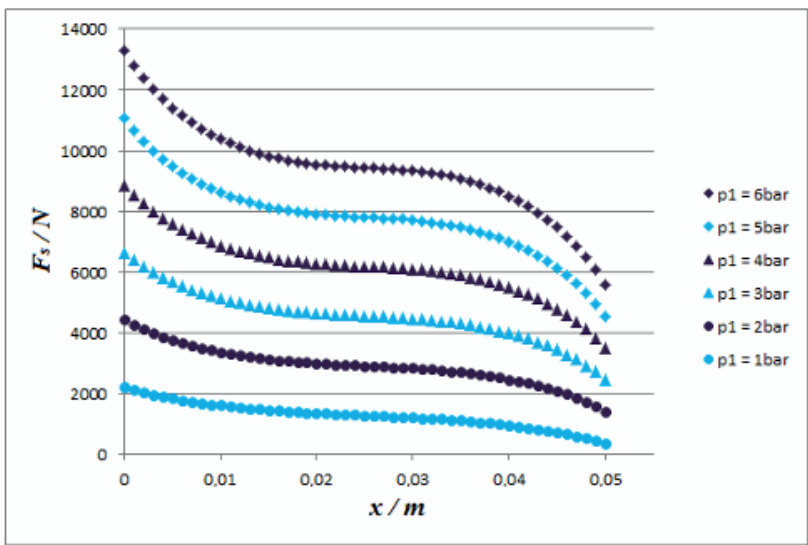

Figure 7. Static characteristics created based on mathematical model, diaphragm motor Rexroth 1020100000

Position sensor $x$ is at one end fixedly attached to the frame of the measuring device and at the other end is based on the moving part under mass load HZ. Between the mass load and the measured motor is positioned force sensor F. In the lower branch is then the distributor R2 and pressure multiplicator MT, by which the increased pressure entering the proportional pressure regulator PR. The proportional pressure regulator PR maintaining 
pressure $p_{1}$ in the measured motor $\mathrm{M}$ at a constant value. Before the motor is pressure sensor. All measured values are transferred using the measuring card MF 624 to PC and processed and recorded using Matlab-Simulink software. This program also provides pressure regulation in the measured motor.

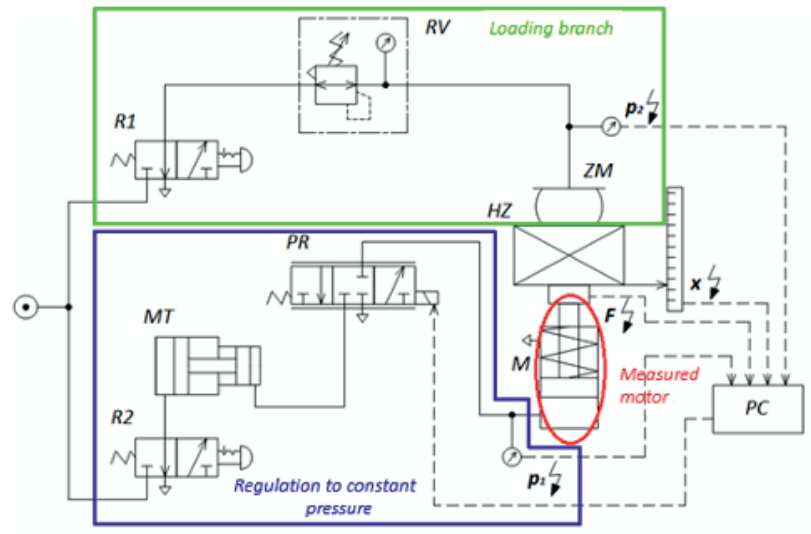

$R 1, R 2-3 / 2$ distributors, $R V-$ reducing valve, $P R$ - proportional pressure regulator,

$M T$ - pressure multiplicator, $Z M$ - burdening motor, $H Z$ - mass load, $M$ - measured motor

Figure 8. Scheme for measuring of diaphragm motors

\section{Conclusion}

After inspection of the available diaphragm motors catalogs they are shown only working conditions and an outer construction sizes of these motors. It also listed force on the end of piston stroke. However this value is only a constant and not very informative. There is also shown the range of spring force and maximum stroke of motor. There are no characteristics included or course of force effects that would describe the behavior of these motors.
From this perspective the determination of such characteristics is very useful and created mathematical models can be used in industrial practice.

When we compare the results of mathematical models with the experimentally observed values it was achieved very good agreement in the course of static characteristics $F_{s}=f(x)$. Results of the total force at a constant pressure in the model was slightly higher compared with the experiment. This fact could be due to many different factors, eg. not exactly set the module of elasticity of the membrane material, because it is elastic rubber part with textile liner. Another factor affecting the value of the total force is a significant change in the shape of the membrane and thus its effective area during the stroke. Consideration should also take possible inaccuracies in the experimental verification of these motors, as manufacturers in their documentation not provided any information, which can be compared with experimental results. Because this deviation occurred in two different types of diaphragm motors, at approximately the same size, it was performed on the model correction coefficient of the static force $F_{S}$. This coefficient reduce the static force by a constant value $13 \%$. The results of adjusted model are compared with measured values is shown in Figure 9.

To accurately describe the above moderate value deviations it would be needed to experimentally measure the multiple pieces of the same type motors and verify or modify the experimentally observed data. On the base of described mathematical models can be compilate dynamic behavior of diaphragm motors.

In Figure 10 is shown a complete schema of the mathematical model of diaphragm motor.

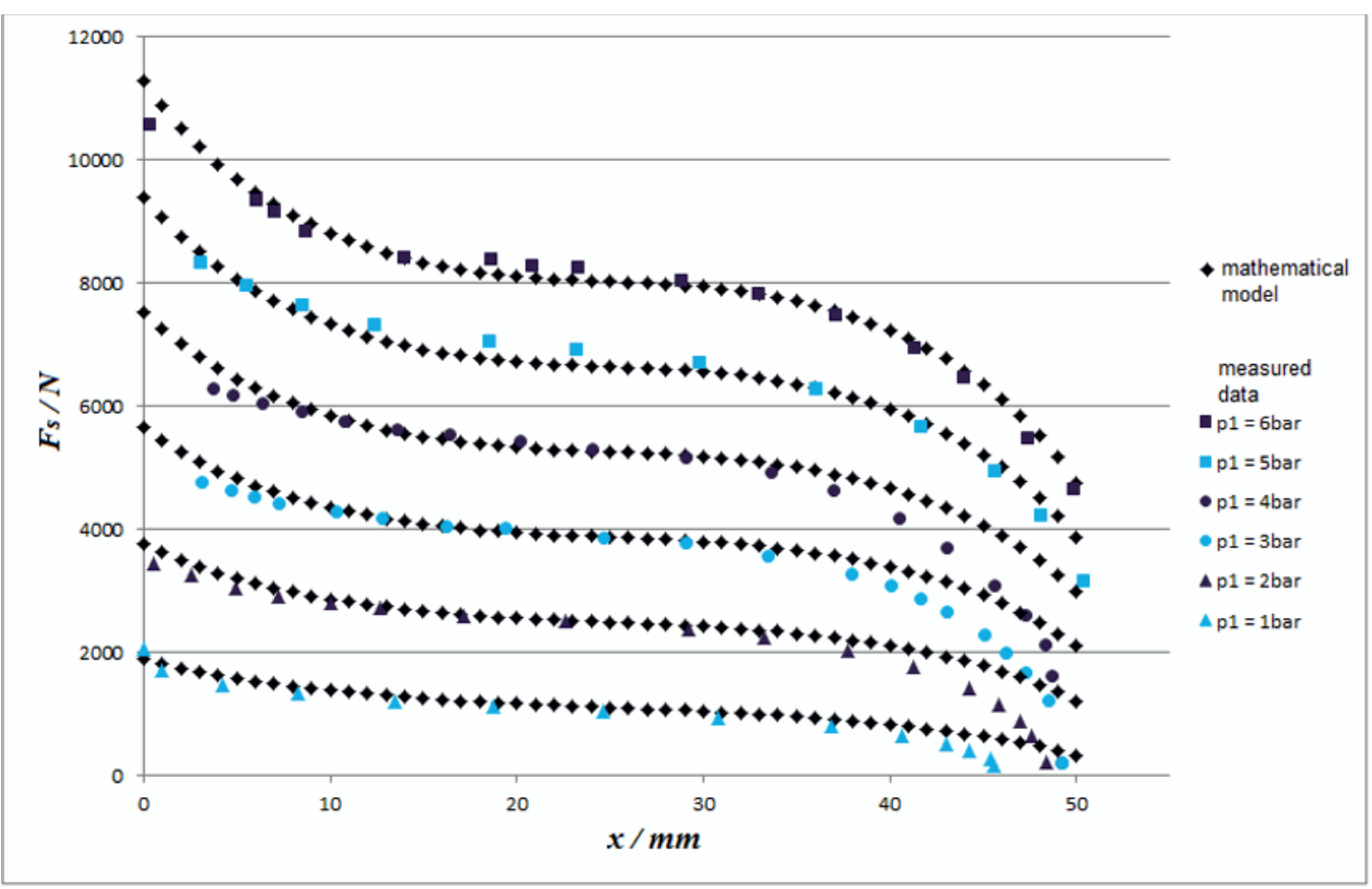

Figure 9. Comparison results of mathematical simulation with experiment, diaphragm motor Rexroth 1010200000 


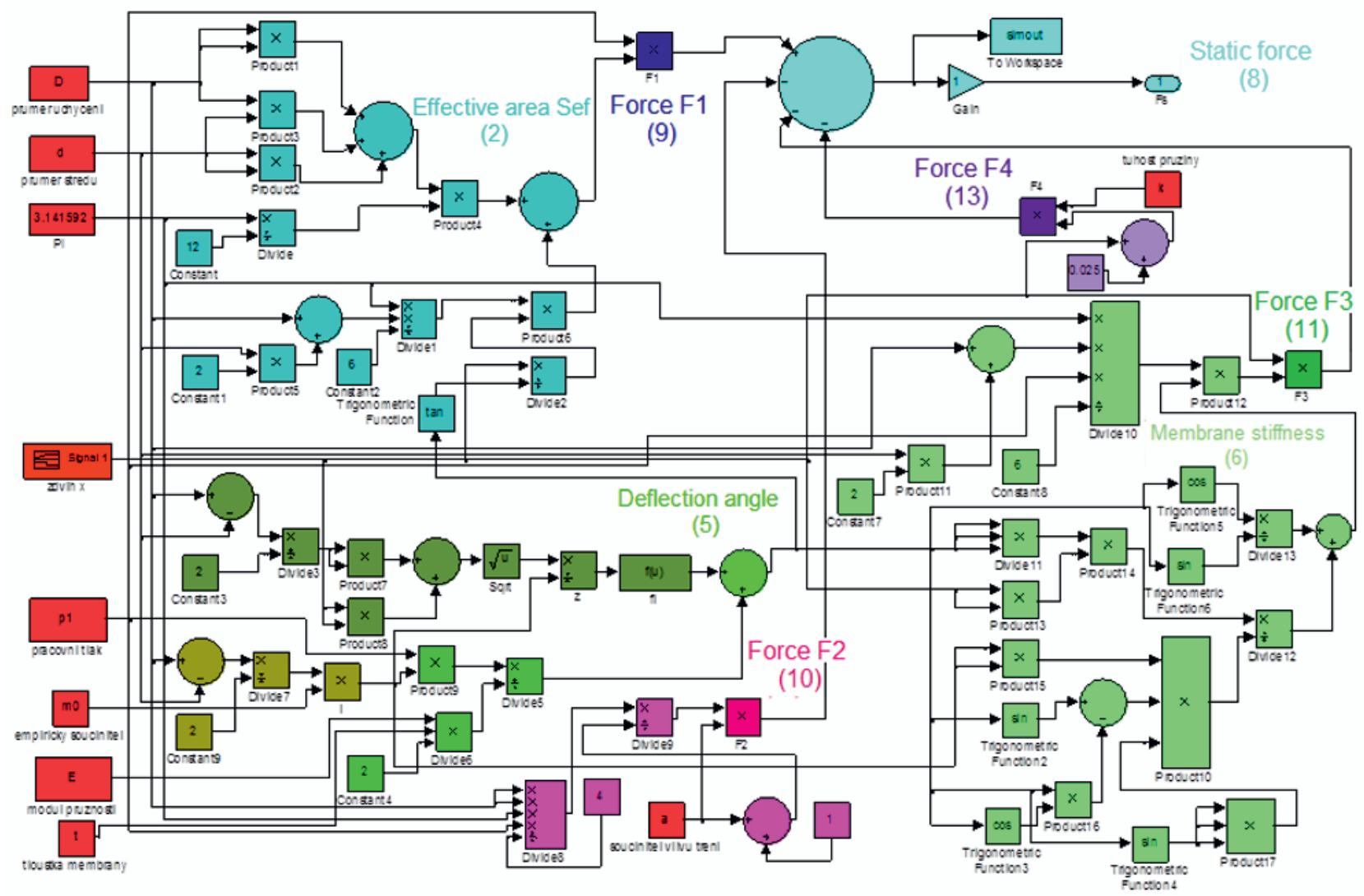

Figure 10. The mathematical model of the diaphragm motor

\section{References}

1. K. Fojtášek, J. Kopáček, L. Dvořák: Pneumatické motory s elastickými pracovními členy, Sbornik př́spěvků 30. Setkání kateder mechaniky tekutin a termomechaniky, Špindl. Mlýn, p.37 (2011)

2. K. Fojtášek, J. Kopáček: Pneumatic motors with elastic working elements and their mathematical modeling, Journal of the 21. International conference on hydraulic and pneumatic, p.171 (2011)

3. J. Kopáček: Pneumatické mechanismy I. Pneumatické prvky a systémy, Ostrava, (2005)

4. V. L. Vodjanik: Elastičnyje membrany, Moskva (1974)

5. K. Fojtášek: Modelování a experimentální ověření chování elastických pneumatických pracovních prvků, Disertační práce, Ostrava, (2013)

6. M. Kozubková: Dynamika hydraulických systémů, Ostrava, (2005)

7. K. Fojtášek, L. Dvořák, J. Kopáček: Měření statických charakteristik pneumatických motorů s elastickými pracovními členy, Hydraulika a pneumatika, 1-2, p.9, (2012) 